\title{
POLÍTICA EDUCACIONAL, ENSINO SUPERIOR PÚBLICO \& PESQUISA ACADÊMICA: UM JOGO DE XADREZ "ENCASSINADO"
}

\section{Educational Politics, Public Superior Education \& Search Academica: the Game of Chess}

\author{
Maria de Lourdes Pinto de Almeida ${ }^{1}$ \\ Paulo Marcos da Silva ${ }^{2}$
}

\section{Resumo}

Neste texto pretendemos abordar criticamente algumas dimensões da configuração das políticas educacionais, no discurso neoliberal, tendo como foco de análise a pesquisa desenvolvida na UNIVERSIDADE PÚBLICA no final do século XX e início do século XXI. Procuramos demonstrar, a partir de uma abordagem Histórica, a dimensão educacional, característica de toda lógica hegemônica, reconhecida como um importante espaço de construção e (de)formação de consciência política por intelectuais conservadores que, em meados do século XX, traçaram em suas metas profissionais as caractenísticas da base teórica do neoliberalismo. Na seqüência, apresentaremos algumas considerações gerais sobre como se constrói a retórica neoliberal no campo educacional. Nosso objetivo foi o de questionar a forma do Estado Neoliberal, pensar e projetar a política educacional na pesquisa acadêmica desenvolvida pela Universidade Pública. Finalizaremos destacando algumas das mais evidentes conseqüências dessa farsa rotulada pelo Banco Mundial, BIRD e FMI.

Palavras-chave: Política do ensino superior; Gestão da educação universitária.

1 Docente pesquisadora do Grupo de Estudos e Pesquisas de Educação Superior da UNICAMP; Docente pesquisadora do Grupo de Estudos e Pesquisas em Ecologia Humana na USP. Campus de Piracicaba; Professora convidada de Metodologia da Pesquisa da USP - ESALQ. E-mail: malu04@uol.com.br

2 Graduado em Filosofia pelo Instituto de Filosofia Ciências Humanas da Universidade Estadual de Campinas. Mestrando em Filosofia pelo FFLCH da Universidade de São Paulo. Professor de Filosofia da Rede Pública Estadual de São Paulo. 


\section{Abstract}

In this text we intend critical to approach some dimensions of the configuration of the educational politics, in the liberal speech, having as focus of analysis the research developed in the UNIVERSITY PUBLISHES in the end of century XX and beginning of century XXI. We look for to demonstrate from a Historical boarding, the educational, characteristic dimension of all hegemonic, recognized logic as an important space of construction and (de)formation of conscience politics for intellectual conservatives who, in middle of century $\mathrm{XX}$, had traced in its professional goals the characteristics of the theoretical base of the liberalism. In the sequence, we will present some general considerations on as if it constructs the liberal rhetoric in the educational field. Our objective was to question the form of the liberal State, to think and to project the educational politics in the academic research developed by the Public University. We will finish detaching some of the evidences consequences of this humbug friction for the World Bank, BIRD and FMI

Keywords: Educational politics; Academic's research; Public-privatecapitalism.

\section{Introdução}

"O Estado, enquanto provedor do bem-estar social, estava integrado na mentalidade moderna de conquista de melhorias individuais e sociais pelo uso dos mecanismos racionais. A frustração desse modelo ensejou a virada paradigmática que coloca o Estado a serviço de um novo modelo econômico global..." (...). "Osdebatespolíticosqueassinalam a tran sformação do Estado transbordam para o campo educacional. Se o modelo do 'welfare state'se transforma, isto não pode ficar sem reflexos sobre a universidade que se colocava a serviço desse Estado" (GOERGEN).

O discurso Liberal possui defesas inauditas e no seu mais 'sublime' espectro é defendido como a 'maravilha do mercado'. Pode-se destacar como fonte desse discurso o princípio da redução máxima da função dos Aparelhos Ideológicos do Estado. Dito isso, podemos destacar que historicamente os liberais surgiram em contraposição às doutrinas mercantilistas, admitindo a limitação das regulamentações internas, eram ainda favoráveis a uma política governamental ativa, destinada a aumentar a participação nacional no âmbito dos mercados internacionais.

A historiografia que trata da questão sobre a relação UniversidadeEstado revela uma predominância do uso privado da pesquisa acadêmica desenvolvida pelas Instituições de Ensino Superior. Esta dimensão privada da investigação universitária possui duas vertentes: a econômica e a político- 
ideológica. A primeira resulta do processo de empresariamento na esfera social e cultural envolvendo, principalmente, a educação e a saúde, as quais o Estado procura se desvincular, repassando-as ao domínio privado. Este, diante de uma crescente demanda, aliada à ineficiência do Estado Liberal Capitalista de cumprir suas tarefas, visualiza e invade com suas concepções de mercado e acúmulo de capital qualquer área de produção de conhecimento.

Se a sociedade capitalista se define pelas contradições que desenvolve, a sociedade nela engendrada é dinâmica e inacabada. Portanto, a sociedade burguesa é meramente mais um estágio no interior do processo histórico, sendo, assim, sujeita a ser superada.

As classes economicamente abastadas monopolizam as ciências, as artes e toda manifestação da dimensão cultural. O conhecimento passa a ser um instrumento de apropriação material e espiritual nas mãos da classe economicamente dirigente que a usará como meio de extorsão de mais-valia. Separados dos meios de produção de vida material, tal elite produz um saber incoerente com a situação nacional. As instituições Civis e Políticas nas quais atuam - mormente as de caráter cultural como a universidade, por exemplo reproduzem um fenômeno inerente à força do capital.

A produção científica e cultural se desenvolve em frações aparte do setor produtivo, no âmbito da superestrutura. A divisão do trabalho na sociedade capitalista produz um resultado perverso, pois a separação da atividade intelectual - manual em práticas (des)conexas - permite uma contínua reconstrução do mundo burguês, dificultando a mobilização da sociedade e valorizando uma pseudo-ordem social vigente. É por isso que a teoria materialista vê os homens como produtos da circunstância: homens modificados são produtos de circunstâncias díspares e de educação alienada; tal teoria esquece que as circunstâncias devem ser regidas precisamente pelos homens e que 0 próprio educador precisa ser educado.

O desenvolvimento das forças produtivas gera, por meio de um crescente movimento de reivindicações populares, uma ascendente negação da ordem burguesa nas esferas culturais e sociais, como, por exemplo, nas Universidades Públicas. Na medida em que essa reivindicação se amplia, se agudizam os conflitos de classe, os quais obrigam a ordem da classe burguesa a permanentes reformulações de seu statusquo. Este processo traduz uma situação de crise. No decorrer do tempo, o processo revela que o espaço entre um re-ordenamento e outro é cada vez mais curto tornando, conseqüentemente, a crise, permanente.

A sociedade civil e política detêm uma relativa autonomia, uma vez que cada uma delas se caracteriza por uma materialidade própria regida pelos instrumentos ideológicos do Estado e por um organismo correspondente que se manifesta na disposição da vida social, articulando e reproduzindo as relações de poder (ditadura e/ou hegemonia). 
Como se pode notar, a estrutura hegemônica é essencial na realização da sociedade civil. A busca do consenso é condição sine qua non da dominação do Estado por uma única facção. Não basta que uma classe seja dirigente na sociedade, é preciso que seja também dominante no poder. A sociedade civil tornando-se uma esfera específica do Estado, mas mantendo certa autonomia, vai funcionar como mediação necessária entre a base econômica e o Estado, em sentido restrito.

A supremacia como síntese unificadora de hegemonia e de dominação não traduz a fundação e muito menos a homogeneidade delas. Sucede que na correlação de forças entre as classes um projeto político-cultural torna-se predominante. Entretanto, as funções consensuais ou coercitivas, existentes em um Estado Capitalista em que uma ou outra esfera prevaleça, dependem da autonomia relativa da sociedade política e civil pertencentes a uma ou outra dessas esferas, surgidos mediante maior ou menor grau de desenvolvimento político. A independência cada vez maior entre essas esferas cria o espaço democrático ou autoritário. Surge, portanto, a possibilidade do confronto ideológico e cultural no interior dos conglomerados privados de hegemonia como estratégia fundamental das classes dominadas para a criação e fundação de uma nova ordem social.

A Escola, como um todo, e a Universidade, em particular, em congruência com a ordem social vigente, tornam-se por excelência sítios sui generis de hegemonia, nos quais se difundem as ideologias da classe dominante e, por conseguinte, passam gradativamente a se formalizar e se sedimentar em espaço privilegiado de produção de ciência e de difusão de pensamento de todos os matizes (da classe dominante), ainda que conflitantes entre si. A dinâmica deste processo, ao modificar as atribuições atemporais do conhecimento, para responder à provação imediata do capital hegemônico, provoca uma teatralização do ethos intelectual nas instituições educacionais publicas.

Unilateralmente apenas é possível, neste ínterim, configurar o pseudo-intelectual em uma dinâmica sectária do dominus meus, a saber, do conhecimento regido pelo capital; na sociedade modema a relação Capital x Trabalho tem olhos de rei para tais judiciosos intelectuais.

O conhecimento produzido pela universidade é sabido como público pelo fato de se engendrar em uma instituição não privada. Entrementes, em nosso vívido ethos acadêmico, esse tal conhecimento geneticamente corporificado produz a marca do interesse privado, o qual é gerado pelas artimanhas do mercado representadas pelo deleite do empresariado. Conseqüentemente, crer em uma socialização do saber é tão cínico quanto a cega religião de que há imparcialidade quando se vincula Educação e Capital; mas é peremptória, sim, a apropriação do conhecimento, que jaz no sistema de patentes e nos convênios que outorgam a grupos determinados do setor produtivo o direito exclusivo sobre o saber de uma pesquisa, da universidade pública. 
Compreendamo-nos que a apropriação do conhecimento científico não é um privilégio do atual neoliberalismo que epidemiza o ethos acadêmico. Por mais público que pareça o modelo merthoniano ${ }^{3}$ de ciência 'autônoma', que idealiza um projeto de pesquisa totalmente desvinculado do setor produtivo, os interesses que a academia atende sempre privilegiam e destinam-se a um grupo. $\mathrm{O}$ que caracteriza a nova forma de apropriação do conhecimento é a abertura ao mercado, o qual redefine as relações entre os "produtores" do conhecimento e os seus "consumidores". Dentro desse ethos acadêmico, os interesses econômicos financiam e direcionam o destino da pesquisa científica. O confronto ideológico contemporâneo edifica-se com a problemática da legitimidade e legalidade desse processo de mercantilização.

Assim (re)estruturada, conforme a lógica do mercado global, a universidade funde-se indubitavelmente à lei das pesquisas aplicadas, expropriando a virtude do incentivo ao desenvolvimento de projetos em áreas de pesquisas mediatas. Com isso, a universidade pode, por um lado, contornar as dificuldades financeiras que se tornaram problemáticas com a política de reestruturação do próprio Estado conforme a lógica da globalização. O desaparecimento do espaço público, caracterizado pela contínua perda de poder decisório e de soberania do Estado-Nação, reflete-se abissalmente na universidade pública em sua busca de financiamento. Contudo, por outro lado, essa tendência de mercantilização do conhecimento pode ser revertida com processo de agenciamento do conhecimento científico; a universidade pública pode buscar alternativas para não se reduzir a um mero balcão de tecnologia, ela deve interagir com o setor produtivo por meio de órgãos gerenciadores de pesquisa criados e mantidos pela própria Instituição Educacional Pública, ${ }^{4}$ tais órgãos devem elaborar projetos conveniados a Empresas Estatais, com pesquisadores mantidos pela Academia.

Nesse cenário mundial, os pesquisadores perdem identidade devido à flexibilização do trabalho, ao enfraquecimento dos sindicatos e ao desmonte do sistema de proteção acadêmica fundada em direitos historicamente e arduamente adquiridos. Trata-se, na verdade, de um processo econômico que desconfigura diretamente os Estados-Nação que ainda que minimamente garantiam os direitos e promoviam 'bem-estar' de acordo com as urgências políticosociais da sociedade civil. Entretanto, nesta era da irracionalidade e de inversão de valores que estamos vivenciando, mesmo esse ínfimo e ambíguo conceito de Público, o qual matematiza o já irrisório contrato capital $\mathrm{x}$ trabalho mediado

3 Segundo Merton, a Universidade Pública teria como papel fundamental o de produzir ciência desvinculada de interesses econômicos e sem financiamento do setor produtivo. O responsável pelo desenvolvimento do protótipo da investigação acadêmica deve ser o Estado.

4 Tais como ETT - Escritório de Transferência de Tecnologia da UNICAMP e o UNIEMP Escritório de Transferência de Tecnologia da Universidade para Empresa. 
pelo Estado, tende a desaparecer com a mundialização do capital que acarreta, como avassaladora conseqüência, a sedimentação do 'caos' educacionalpedagógico e este inavertidamente re-produz a globalização da pobreza política e econômica.

O Estado de bem-estar social representou, em um determinado momento histórico, uma força contrária ao movimento uniforme do referido contexto, neste intercâmbio o capital homogeneamente negociou, soube jogar dar as cartas - para manter-se e vingar-se como o império dos homens. ${ }^{5}$ Com a globalização, o capital irascivamente (re)amolda seu vigor e republica posições antes intocadas, imprimindo, assim, letras cifradas de uma suposta 'nova-moeda', a qual ecumenicamente gera espoliação e sub-trai os controles nacionais. Embora a maioria da população, inclusive a brasileira, não tenha acesso aos vindouros benefícios ecumenicamente rotulados de públicos, 0 Estado teima em apresentar propostas com teorias susceptíveis à regra do Mercado, as quais, quando prometem, reduzem a participação da sociedade civil nos benefícios conquistados pela parceria Estado-Empresa-Capital-Educação-Sociedade.

O Estado-Nação, leia-se Brasil, é orquestrado de modo a acentuar a dependência

econômica e a (des)nacionalização das mais diversas riquezas, desde as ligadas ao subsolo até as Instituições Estatais. O final apocalíptico do Estado-Nação, que hora já se mostra, assenta-se, sobretudo, na transferência de patrimônio nacional ao capital internacional. A universidade pública é patrimônio nacional universal; globalizá-la e/ou privatizá-la desmonta a arquitetura científico-cultural, melhor dizendo, a universidade destrói-se a si mesma e o espaço pluri-nacional que, em um país como o Brasil, com suas contradições e diversidades, poderia expressar as identidades e defender os interesses multiétnicos, expressando, deste modo, a luta contra a desigualdade social.

Ora, como esta práxis política não faz e nunca fez parte de nossa História, a maior parte da população brasileira está cada vez mais expropriada do modo de produção, empobrecida, e incapaz de reagir ao imperialismo expresso na globalização.

O conceito de público se efetivou, ainda que de modo precário, no Estado-Nação, no século XVIII, no período da Revolução Francesa com a escrita da Declaração dos Direitos Humanos. Com a mundialização do capital, a universidade pública verte-se, como o Estado-Nação, em decadènce. Esta aporia, que longe se encontra da contenda final, necessita de uma ação hegemônica que funde os alicerces do pilar da soberania nacional e esta, por mais tendenciosa e fragmentária que seja, preserve o interesse nacional, no sentido

5 Vale lembrar o ditado popular 'o dinheiro está na cabeça e não no bolso [dos homens]'. 
de eliminar cada vez mais a exclusão social e as formas de dominação econômica. Em tal contexto, a articulação governamental é essencial. Cabe a ela lutar contra as tendências de internacionalização da economia, revertendo o processo de sucateamento da Instituição Nacional ou sua incorporação às multinacionais, resgatar a capacidade do Estado de interferir na economia por meio da regulação do capital ou de investimentos em setores fundamentais (tais como educação e ciência), e reverter o processo de privatização das empresas e universidades públicas.

Com a globalização da economia, a academia pública domestica sua identidade: isso se comprova pela constante perda de autonomia Universitária, principalmente, as que respondem à investigação científica, para não verbalizarmos: ensino, extensão e representatividade política (os rumos da pesquisa são decididos, em sua maioria, pelas fontes financiadoras). Deixar o financiamento ao mérito do mercado significa atrofiar e esquartejar as áreas de pesquisas fundamentais e 0 , conseqüente, amordaçar do Estado Constitucional. Nesse sentido, cabe salientar que os órgãos governamentais devem dar prioridade aos projetos de pesquisa voltados ao atendimento da sociedade civil menos favorecida economicamente, pois a tendência é que esses, ainda que trabalhando com dinheiro público, tendam a financiar projetos diretamente vinculados aos interesses do setor produtivo. Com isso não se trata de negar ou suprimir os convênios da Universidade Pública com a iniciativa privada, mas, sim, de criar, preservar e ampliar as fontes públicas de financiamentos. A veiculação da agência de fomento à pesquisa não visa garantir 0 "desinteresse" do conhecimento tal qual propõe o modelo mertoniano, pois, em nosso contexto histórico permeado pelo individualismo crescente e pela transformação da educação em mercadoria de uso e de valor, a ciência inclina-se a, cada vez mais, assumir o um caráter de atividade "interessada".

O "comunismo" em ciência, segundo Merton, deve ser conceituado de forma que se traduza a socialização do saber por meio da participação dos pesquisadores em Congressos, Eventos Científicos, Grupos de Estudos e Extensão, Núcleos Nacionais e Internacionais de Pesquisas Interdisciplinares, divulgação da construção e da importância da investigação cientifica nos meios de comunicação de massa, além da inserção dos resultados científicos em periódicos nacionais e internacionais. Tudo isso é non sense quando há entre a Universidade Pública e o Setor Produtivo um matrimonium, porque a Universidade assina conivência de silêncio, a qual é uma das declarações feitas pelos Mercantilistas. No que toca às agências de fomento às pesquisas, em boa tida e cordatamente, o financiamento para ser liberado necessita de critérios que exprimem os devaneios/nuances mercadológicos (todo devaneio é algo, grosso modo, de insight, assim é o mercado), produzindo, portanto, a delimitação da socialização do saber a grupos restritos de (a)discussão. A 
pesquisa seqüestra-se e enclausura-se a si mesma em uma 'camisa de força' e o pesquisador monologa-se em seu vitimado paradigma teórico de referência e discussão. A autonomia já está totalmente deliberada, antes da escolha do tema de pesquisa e até a finalidade (a)social desta.

Frente às tendências paradigmáticas propostas à ciência percebe-se que a nulidade de autonomia é extensiva à pesquisa básica. Quanto à pesquisa aplicada não se deve esperar avanços já que mesmo a pesquisa de base é oportunada pelo oportunista abstrato, o capital. Diante desse modelo de Estado Liberal que temos no Brasil, dá-se com muita dificuldade o entendimento da sociedade civil e política no que tange à totalidade do fato histórico. Isso se reflete na Universidade Pública com a conseqüente fragmentação e estagnação do conhecimento acadêmico que é usado na pesquisa universitária. 0 saber científico é concomitante, quer dizer, a ciência básica e a aplicada se integram em um movimento de total dependência, não podendo sofrer distinção e/ou priorização de financiamento das agências de fomento em detrimento de uma determinada área de investigação. $\mathrm{O}$ aumento de incentivo ao investimento público em pesquisa básica possibilitaria ampliar o leque das aplicações da ciência aos menos favorecidos economicamente? Qual é o objetivo e a quem se destina a ciência desenvolvida na Universidade Pública diante desse caos lógico determinado por um Estado que prega o mínimo para 0 desenvolvimento social e o máximo para as relações que envolvem o aumento do capital? Essas questões nos levam a fazer algumas inferências mentais a respeito das causas e das conseqüências dos problemas enfrentados pela pesquisa aplicada e tendem a suscitar novas tendências de fragmentação na pesquisa básica, porque dentro dos critérios de suposta qualidade exigidos pelo mercado estão o imediatismo, a rapidez do processo e a capitalização do produto final. Esses critérios são opostos aos utilizados pela Comunidade Científica. E, então, perguntamos: a pesquisa desenvolvida na Universidade Pública tem preço? Quanto vale, é por quilo? How much, Sir?

Enquanto prevalecer na política educacional a orientação de caráter neoliberal, a estratégia da resistência ativa será a nossa arma de luta. Com ela nos empenharemos em construir uma nova relação hegemônica que viabilize as transformações indispensáveis para adequar a educação às necessidades e aspirações da população brasileira (SAVIANI, 1997, p. 238).

O modelo mertoniano, ou de "ciência autônoma", não está totalmente superado; ele apenas não é único. Junto a este modelo desenvolve-se outro que é a antítese daquele, no qual se ambienta a universidade pública, a contemplação de ambos no âmago da Universidade insere-se em convênios que vinculados às pesquisas aplicadas devem ser angariados pelo setor público, e não pelos setores empresariais vigentes. 
Política educacional, ensino superior público \& pesquisa acadêmica: um jogo de xadrez "encassinado"

\section{Considerações finais}

(...) presencia-se uma mudança de paradigma na produção das políticas públicas em geral e, (...), na educação superior no Brasil, também conhecido como processo de mercadorização da esfera pública. O atual governo, acentuando tendências anteriores, inequivocamente subsume a educação superior a uma política de gastos, de redução do déficit público, isto é, ao econômico, às regras do mercado. As políticas públicas tomaram-se, com esta mudança, políticas públicas baseadas no 'paradigma da oferta do Estado'(orientado, (...), por organismos multilaterais com destaque para 0 Banco Mundial), e não no 'paradigma de demanda da sociedade', de acordo com suas necessidades. O Estado oferece educação superior segundo sua concepção, quem quiser e puder que se habilite a seu usufruto e se inclua na organização so cial patrocinada pelos atuais detentores do poder estatal. Posto que as políticas para a educação superior são subsumidas a uma política de gastos, ao mercado e ao econômico, não se trata de política genuinamente educacional, as de uma política econômica, produzida essencialmente por organismos financeiros transnacionais, onde se destaca o Banco Mundial, e assumida pelo atual governo (SILVA JR; SGUISSARD, 1999).

Na década de 70 do século XX, tínhamos uma fraca demanda de convênios por parte da empresa privada nacional, o que favoreceu o desenvolvimento de programas de pesquisa das Instituições de Ensino Superior Públicas em parceria com as empresas estatais. ${ }^{6}$ Entre as décadas de 1970 e 1980 tais parcerias, entre as empresas estatais e a Universidade Pública, passam a ser desmontadas. Na década de 1990 com a implantação do Estado Liberal no Brasil e o início de um processo de privatização de Empresas Estatais, a Academia acode a parcerias com o setor produtivo. Essas parcerias começaram a se intensificar devido a uma suposta qualidade científica de pesquisa, a qual é mensurada pelo quesito de quantidade proposto pelo modelo econômico da mundialização do capital. Nesse sentido a universidade foi cooptada pelo mercado.

Neste contexto histórico, de invasão das facções organizadas pertencentes à sociedade política e civil, as quais controlam as pesquisas da universidade pública, percebe-se que as diretivas das instituições educacionais são resultados de uma luta ideológica partitiva, e estrategicamente articulada pelos organismos que deliberam as diretrizes político-nacionais, os quais juramentam a hegemonia da classe dominante. Os resultados desse jogo de xadrez, tendencioso e heterogeneamente ambíguo, porém radicalmente lógico do capital, dá como "xeque mate" a flexibilização e privatização do conhecimento humano. A universidade em xeque traduz aos quiçá-intelectuais (e

6 Como exemplo podemos citar a parceria entre Unicamp, Telebrás e CPQd. 
para a nação num todo) a idéia de que a instituição pública não pode mais depender da competência estatal para o desenvolvimento de seus protótipos de investigação, e em virtude desse xeque, os investigadores perdem sua identidade, sentem o fragilizar das pesquisas, e por determinação da própria construção da História, transformam-se em meros 'gerenciadores de recursos', sendo assim, acodem a um jogador mais perspicaz, no caso o capital, não obstante, este move as peças do tabuleiro unilateralmente para proveito de seu próprio destino.

Aos intelectuais comprometidos com uma universidade pública plural cabe a luta para reverter as tendências do xadrez encassinado. A disposição de espírito deste jogo de xadrez, que está enclausurado em um corpo capitalizado pelo "Rei do Cassino", é perversa e ideologicamente emblemática porque, por um lado, aos esotéricos deste jogo o resultado e a predestinação da lição são sabidos, mas, por outro lado, aos exotéricos eles, os resultados, estão ocultos, são um mistério - um jogo (i)racional, (a)lógico, como parecem ser as 'adversidades' de uma conta econômica.

Que os intelectuais tomem as peças pseudo-irracionais e capturem 0

Rei.

Segundo Licha, as regras do jogo da globalização escondem o argumento primo-unívoco do "neminem iuva, imo omines, si forte conducit, lae$\mathrm{de}^{\prime \prime}:{ }^{7}$

El fin de las políticas competitivas en los países en desarrollo es primordialmente ideológico, ya que, por una parte, encubren el interés monopólico que impulsa y dicta tal política, y por la ostra, crean la ilusión de que todos los países que se someten a las nuevas reglas del juego tienen grandes e iguales oportunidades de salir victoriosos en esta contienda tecno-económica. Lo que en realidad ocurre es que a través de estos procesos de globalización se monopoliza la economía, se corporativiza-privatiza la producción del conocimiento y se reordenan las relaciones socioeconómicas entre países y regiones, de acuerdo a un nuevo patrón que exacerba las disparidades e inequidades propias del viejo modelo (LCHA, 1996, p. 211).

\section{Eiaintelectuais! Eis as peças, tomem-nas, capturem o Rei!}

Ora, tal infenso duelo envolve uma plataforma de combate ampla, em um bloco histórico de resistência ativa, que imponha novas tendências às instituições nacionais, as quais refletirão no interior das universidades públicas. Parte dos pesquisadores "privilegiados" pela interação da Academia ao Setor Produtivo transforma-se em "intelectuais" pre-

"Não ajudes a ninguém, mas prejudica a todos, se acaso fores levado a isso!" Máxima da atitude antimoral egoísta, presente em 'Sobre o Fundamento da Moral', de Arthur Schopenhauer. 2. ed. São Paulo: Editora Martins Fontes, 2001. p. 126. 
sos a uma tendência hegemônica que vai ao encontro da lógica do capital, visando legitimá-la em sua dita práxis científica. São representantes geneticamente legitimadores do ideário de modelo de universidade globalizada. Eles são intelectuais orgânicos não enquanto intelectuais pesquisadores, mas como defensores das novas tendências, portanto, são intelectuais vinculados à classe dominante, às elites privilegiadas com a mercantilização do conhecimento.

Diante desse quadro histórico se faz necessário que a universidade pública venha a se mostrar como espaço político e ideológico, o qual preserve, construa e incentive a pluralidade do conhecimento no ensino, na pesquisa e na extensão. Um problema sempre impertinente é o de saber como as lutas de emancipação em defesa dos interesses da maioria vão atuar para combater os efeitos perversos da globalização, o qual cria novas formas de exclusão social, ao mesmo tempo em que acentua radicalmente e perversamente a desigualdade social e a não eqüidade na distribuição de renda. Contudo, não podemos ser hipócritas a ad infinitum e não percebermos que a eficácia dos movimentos libertários não passa somente pelo manejo da informação e do domínio das novas tecnologias, uma vez que é exatamente neste fato que, desde o início do novo milênio, reside a forma de expansão do capital. Nesta luta competitiva e incomensuravelmente individualista existente nas relações acadêmicas sempre em prol do controle e poder do conhecimento, a disputa tende a aumentar imensuravelmente: o controle das técnicas de produção passa pelo controle das tecnologias de informação. A universidade pública deve, e ainda pode, se edificar como um dos únicos espaços ditos 'revolucionários', dentro do qual todas as tendências emancipatórias devem e podem ser conectadas às novas tecnologias. Destituí-la de seus múltiplos argumentos significa cortar brutalmente suas possibilidades de formação de grupos de resistência, tanto ativos quanto passivos, e isto se verifica principalmente nos países do hemisfério sul, como no caso do Brasil, onde a globalização é imposta de forma unilateral pelos "globalizadores".

E assim joga o Rei do Cassino.

Eia homo sapiens as peças, tomem-nas, capturem o Rei!

Xeque-mate!!

Mort au roi!!! 


\section{Referências}

FRIEDMAN, M. Capitalismo e liberdade. Brasil. Arte Nova. 1977.

GOERGEN, Pedro. A Avaliação Universitária na Perspectiva da Pós-Modernidade, In SOBRINHO, J. D; RISTOFF, D. I. (orgs.). Universidade desconstruída: avaliação institucional e resistência. Florianópolis: Insular, 2000. p. 25.

GRAMSCI, A. Os intelectuais e a organização da cultura. 9. ed. Rio de Janeiro: Civilização Brasileira, 1995.

Brasileira. 1995.

Concepção dialética da história. Rio de Janeriro: Civilização

HAYEK, F. $O$ caminho da servidão. 2. ed. Porto Alegre: Globo, 1977.

HARVEY, David. Condição pós-moderna. São Paulo: Loyola, 1992.

LCHA, I. La investigación y las universidades latino-americanas en el umbral del siglo XXI: los desafios de la globalización., Ciudad. 1996. (Colecíon UDUAL 7).

MARX, KARL Contribuição à crítica da economia política. São Paulo: Martins Fontes. 1977.

. Teses sobre Feuerbach.(III). In: MARX, Karl; ENGELS, Friedrich. Textos. São Paulo. Sociais, 1977. v. 03. p.118.

. O Capital. São Paulo: Nova Cultural. 1985. v. 3.

SAVIANI, D. Educação e questões da atualidade. São Paulo: Livros do Tatu: Cortez, 1991. p. 98.

SCHOPENHAUER, A. Sobre o fundamento da moral. 2. São Paulo: Martins Fontes, 2001.

SILVA Jr, J. R; SGUISSARD, V. Novas faces da educação superior no Brasil. Bragança Paulista: EUDUSF, 1999.

SMITH, A. A riqueza das nações, São Paulo: Nova Cultural. 1985. v. 1. 